\title{
Maternal and neonatal outcome in second stage cesarean section versus first stage: a comparative study
}

\author{
Anusha S. R., Deepak A. V.*, K. J. Jacob
}

Department of Obstetrics and Gynecology, Government Medical College Hospital, Thrissur, Kerala, India

Received: 03 September 2018

Accepted: 28 September 2018

\section{*Correspondence:}

Dr. Deepak A. V.,

E-mail:drdeepakav@gmail.com

Copyright: (C) the author(s), publisher and licensee Medip Academy. This is an open-access article distributed under the terms of the Creative Commons Attribution Non-Commercial License, which permits unrestricted non-commercial use, distribution, and reproduction in any medium, provided the original work is properly cited.

\begin{abstract}
Background: Cesarean Section is the most commonly performed abdominal operation in women all over the world. Variable rates of cesarean section are reported between and within countries. Cesarean section at full cervical dilatation with an impacted fetal head can be technically difficult and is associated with increased trauma to the lower uterine segment and adjacent structures, as well as increased hemorrhage and infection.

Methods: This is a comparative cross-sectional study comparing maternal and neonatal outcome between first stage and second stage cesarean section performed at Govt Medical College Thrissur.

Results: In present study out of 90 cesarean sections 30 were performed in second stage and 60 in first stage.74\% were primigravida in second stage cs group. Arrest due to malposition was major indication for second stage ( $76 \%$ of cases). The most important complication among second stage cs group was PPH (76.7\%) and majority of them needed blood transfusion. These complications were less in first stage cs group. Other Complications like increased duration of surgery (mean=53.3 min), post op fever (36\% post op Wound infection $(13.3 \%)$ was seen in second stage group. Fetal complications like low APGAR scores were seen in $16.7 \%$ of cases compared to first stage group and most of them needed resuscitation.

Conclusions: Women undergoing cesarean section in second stage of labour had increased maternal and fetal morbidity. They required special care and hence Operation should ideally perform and supervised by an experienced obstetrician. Timely decision for cesarean section should be made especially when risk factors for failure to progress are present.
\end{abstract}

Keywords: Cervical dilatation, Maternal morbidity Second stage cesarean section

\section{INTRODUCTION}

Cesarean Section is the most commonly performed abdominal operation in women all over the world. ${ }^{1}$ Recent data suggest that cesarean delivery in labour is associated with increased maternal morbidity compared with cesarean delivery with no labour. One fourth of the primary cesarean section is reported to be performed in the second stage of labour and is more complicated compared to the ones performed in the first stage.

The second stage of labour is defined as the time elapsed from full dilatation of the cervix to expulsion of the fetus.
More importantly, the extension of time given to the second stage of labour has been shown to increase the overall rate of vaginal births without adversely affecting neonatal morbidity. However, maternal morbidities are increased and include operative vaginal delivery, anal sphincter tears, postpartum hemorrhage and emergency cesarean sections $(\mathrm{C} / \mathrm{S}) .^{2}$ Neonatal mortality and morbidity due to hypoxia and fetal trauma remains to be one of the major issues regarding the cesarean section performed in the second stage of labour.

Decision making surrounding cesarean section in the second stage of labour is one of the greatest challenges in 
current obstetric practice. The rates of cesarean sections have risen steadily in the past two decades and may be associated with a disproportionate rise in second stage of cesarean section due to a decline in the use of instrumental deliveries. ${ }^{3}$

Cesarean section at full cervical dilatation with an impacted fetal head can be technically difficult and is associated with increased trauma to the lower uterine segment and adjacent structures as well as increased hemorrhage and infection. ${ }^{4}$ Although the morbidity of cesarean in the second stage of labor has been reported in comparison with operative vaginal delivery, the morbidity in comparison with cesarean delivery in the first stage of labor is less well known.

Although second stage C/S may be necessary, many of them could be avoided by the attendance of skilled senior care provider and implementation of proper instrumental delivery. In second stage $\mathrm{C} / \mathrm{S}$, delivery of the fetus will be difficult due to deeply impacted head in the pelvis, particularly when instrumental delivery is attempted and failed..$^{5}$

In this context, decision made by a senior obstetrician, may determine whether second stage $\mathrm{C} / \mathrm{S}$ is optimal for delivering of a woman with delayed second stage of labour or not. As a result, the Royal College of Obstetricians and Gynecologists (RCOG) recommended the presence of a consultant obstetrician whenever C/S is performed in the second stage of labour (RCOG 2001).

There is controversy over the technique of choice for delivery of the fetal head impacted in the maternal pelvis. Recently; a report suggests that the deeply impacted fetal head can be delivered more safely by using the reverse breech delivery technique (the pull method). The pull method or reverse breech extraction has been studied increasingly over the last decade in several developing countries where obstructed labor is more common. Alternative techniques are less commonly described and include the bimanual push method, Patwardhan technique, and the fetal disimpacting system.

As there is limited study, this hospital based comparative cross-sectional study is taken to compare the maternal and neonatal outcomes of cesarean delivery in second stage of labour versus cesarean delivery in the first stage of labour. Decision making surrounding cesarean section in the second stage of labour is one of the greatest challenges in current obstetric practice.

\section{METHODS}

Study period was from May 2015 to April 2017. Data was collected after getting technical and ethical committee clearance. This is a comparative crosssectional study comparing maternal and neonatal outcome between first stage and second stage cesarean section performed at Government Medical College
Thrissur. Singleton live pregnancies at term and if mother was undergoing cesarean delivery during second stage of labour after satisfying the inclusion criteria will be in the study. Pregnancies with major fetal abnormalities, referred cases in second stage of labour, intrauterine growth restriction, severe PIH, Elective cesarean section were excluded.

The following are the variables of the study- indications for first stage c/s, indications for second stage cs. Intraoperative complications including extension of uterine incision, uterine artery injury, bladder injury, cervical laceration or requirement of hysterectomy, duration of surgery, PPH, need for blood transfusion, post-operative wound infection, puerperal sepsis and maternal death.

The duration of surgery is measured and is defined as the time elapsed between skin incision and skin closure. Extension of primary uterine incision is defined as any uterine wall defect, either laterally into the uterine vasculature, or vertically into the cervix or a contractile uterus that required additional steps to repair.

Uterine artery injury is defined as disruption of vessels that required placing a suture to achieve adequate hemostasis PPH is defined as estimated blood loss $>1000 \mathrm{ml}$. Post-partum endometritis refers to infection of decidua.

It is defined as persistent postpartum temperature $>38.5$ degree cent with malodorous vaginal discharge as well as possibility of uterine tenderness on bimanual examination and no other pelvic infection. Neonatal outcome indicators included birth weight (Gms), Apgar score of newborns at 5mins, fetal injury, septicemia, respiratory distress, admission to nicu and death.

Patients will be examined, and data collected as per proforma. Data will be collected from parturition register and case records on demographics, relevant obstetric data, indications and the intrapartum complications associated with $\mathrm{C} / \mathrm{S}$. Mother and baby will be followed till discharge. Any complications to the mother and baby which developed during their hospital stay were also noted.

\section{Statistical analysis}

Data will be coded and entered into excel sheets and analyzed using Epiinfo/SPSS software. The qualitative data will be expressed in proportions and the quantitative data will be expressed in means and standard deviation. The significance of the results will be assessed using appropriate statistical tests of significance.

\section{RESULTS}

Total no of deliveries were 2030 out of which 510 were cesarean sections. Out of 90 cesarean sections studied in 
the study period 60 sections were performed in first stage of labour (group 1) and 30 sections were performed in second stage of labour (group 2).

Majority were in the age group of 20-25 years $51.7 \%$ in group 1 and $63.3 \%$ in group 2. Majority of the subjects belonged to APL socioeconomic class $58.3 \%$ in group 1 and $60 \%$ in group 2 followed by BPL and Tribal. Primigravida formed the majority of study population
$61.7 \%$ in group 1 and $76.7 \%$ in group 2. Majority belonged to gestational age $38-39 w k s, 56.7 \%$ in group 1 and $43.4 \%$ in group 2. Most important indication for first stage cesarean section is failed induction $33.3 \% \quad 20$ out of 60 cases, Arrest of descent-malposition is the most common indication for second stage cesarean section $76.7 \% 23$ out of 30 cases. Incidence of PPH is more in group 2 that is 23 out of 30 cases $(76.7 \%)$ where as in group 1 it is 6 out of 60 cases $(10 \%)$ only.

Table 1: Distribution of age and parity among subjects who undergone first and second stage cesarean sections.

\begin{tabular}{|c|c|c|c|c|c|}
\hline \multirow{2}{*}{ Variables } & & \multicolumn{2}{|c|}{ Group 1 (60) } & \multicolumn{2}{|c|}{ Group $2(30)$} \\
\hline & & No. & $\%$ & No. & $\%$ \\
\hline \multirow{4}{*}{ Age } & $\leq 19$ years & 6 & 10.0 & 1 & 3.3 \\
\hline & $20-25$ & 31 & 51.7 & 19 & 63.3 \\
\hline & $26-30$ & 19 & 31.7 & 9 & 30 \\
\hline & $31-35$ & 4 & 6.7 & 1 & 3.3 \\
\hline \multirow{3}{*}{ Socio economic status } & APL & 21 & 35 & 10 & 33.3 \\
\hline & BPL & 35 & 58.3 & 18 & 60 \\
\hline & Tribal & 4 & 6.7 & 2 & 6.7 \\
\hline \multirow{2}{*}{ Parity } & Primi & 37 & 61.7 & 23 & 76.7 \\
\hline & Multi & 23 & 38.3 & 7 & 23.3 \\
\hline \multirow{4}{*}{ Gestational age } & $37-38$ weeks & 10 & 16.7 & 12 & 40.0 \\
\hline & 38 weeks 1 day-39 weeks & 34 & 56.7 & 13 & 43.4 \\
\hline & 39 weeks 1 day -40 weeks & 13 & 21.7 & 4 & 13.3 \\
\hline & $\geq 40$ weeks & 3 & 5 & 1 & 3.3 \\
\hline
\end{tabular}

Table 2: Indications of cesarean section.

\begin{tabular}{llllll} 
Grouj 1 & & & Group2 & No. & $\%$ \\
\hline Indications & No. & \% & Indications & 23 & 76.7 \\
\hline Protracted active phase & 9 & 15 & Arrest of descent-malposition & 6 & 20 \\
\hline Fetal distress-non-reassuring CTG & 17 & 28.3 & Arrest of descent-CPD & 1 & 3.3 \\
\hline Failed induction & 20 & 33.3 & Failed vacuum & 0 & 0 \\
\hline Failure to progress & 12 & 20 & & 0 & 0 \\
\hline MSAF, unfavourable cervix & 2 & 3.3 & & 30 & 100 \\
\hline Total & 60 & 100 & & 0 \\
\hline
\end{tabular}

Table 3: Incidence of intra operative and postoperative complications.

\begin{tabular}{|llllll|}
\hline Variable & Group 1 & Group 2 & P value \\
\hline No. & \% & No. & \% & \\
\hline $\begin{array}{l}\text { Need for blood } \\
\text { transfusion }\end{array}$ & $6 / 60$ & 10 & $23 / 30$ & 76.7 & $\mathrm{P}<0.001$ \\
\hline $\begin{array}{l}\text { Uterine tear } \\
\text { Bladder and } \\
\text { bowel injury }\end{array}$ & $0 / 60$ & 0 & $2 / 30$ & 6.7 & $\mathrm{P}=0.04$ \\
\hline $\begin{array}{l}\text { Post op wound } \\
\text { infection }\end{array}$ & $3 / 60$ & 5 & $4 / 30$ & 13.3 & $\mathrm{P}=0.16$ \\
\hline Post op fever & $5 / 60$ & 8.3 & $11 / 30$ & 36.7 & $\mathrm{P}<0.001$ \\
\hline
\end{tabular}

Similarly need of blood transfusion is more in group 2 that is 16 out of 30 cases $(53.3 \%)$ where as in group 1 it is 4 out of 60 cases $(6.7 \%)$. Incidence of uterine tear is more in group 2 that is $6.7 \%$ ) whereas no cases of uterine were reported in group 1 . There were no cases of bowel or bladder injury reported. Post-operative wound infection was seen in 4 out of 30 cases in group 2 $(13.3 \%)$ compared to 3 out of 60 cases in group $1(5 \%)$. Post-operative fever was seen in 11 out of 30 cases in group $2(36.7 \%)$ compared to 5 out of 60 cases in group 1 $(8.3 \%)$.

There were no cases of maternal deaths reported. The mean operative time was more group 2 (53.3 $\mathrm{min})$ compared to group 1(41 $\mathrm{min})$. The mean length of hospital stays in group 2 is 6.9 days which is higher than group 1 which is 5.2 days. APGAR $<3$ at 5 min was seen in 5 out of $30(16.7 \%)$ cases in group 2 whereas no cases were reported in group 1. 
Table 4: Operative time and length of hospital stay.

\begin{tabular}{|c|c|c|c|c|c|c|}
\hline Variable & Group & No & Mean \pm SD & Range & $\mathrm{t}$ : unpaired $\mathrm{t}$ test & P value \\
\hline \multirow{2}{*}{ Operative time(min) } & Gr1 & 60 & $41.0 \pm 3.8$ & $35-50$ minutes & \multirow{2}{*}{12.91} & \multirow{2}{*}{$<0.001$} \\
\hline & Gr2 & 30 & $53.3 \pm 5.1$ & $45-60$ minutes & & \\
\hline \multirow{2}{*}{ Length of hospital stay } & Gr1 & 60 & $5.0 \pm 0.8$ & 5-9 days & \multirow{2}{*}{3.23} & \multirow{2}{*}{0.003} \\
\hline & $\mathrm{Gr} 2$ & 30 & $6.9 \pm 2.8$ & 5-15 days & & \\
\hline
\end{tabular}

$\mathrm{P}<0.001, \mathrm{HS}$

Respiratory distress was seen in 16 out of 30 cases in group $2(53.3 \%)$ where as in group 1 there were 19 out of 60 cases $(31.7 \%)$. Resuscitation was needed $53.3 \%$ cases in group 2 where as $30 \%$ cases in group 1 . There were 3 neonatal deaths reported in group 2 where as in group 1 there were no neonatal deaths

Table 5: Neonatal complications.

\begin{tabular}{|llllll|}
\hline Variable & Group 1 & \multicolumn{2}{c}{ Group 2 } & P value \\
\hline $\begin{array}{l}5 \text { min } \\
\text { APGAR }<3\end{array}$ & 0 & 0 & $5 / 30$ & 16.7 & $\mathrm{P}<0.001$ \\
\hline $\begin{array}{l}\text { Respiratory } \\
\text { distress }\end{array}$ & $19 / 60$ & 31.7 & $16 / 30$ & 53.3 & $\mathrm{P}<0.05$ \\
$\begin{array}{l}\text { Need for } \\
\text { Resuscitation }\end{array}$ & $18 / 60$ & 30.0 & $16 / 30$ & 53.23 & $\mathrm{P}=0.04$ \\
\hline $\begin{array}{l}\text { Neonatal } \\
\text { death }\end{array}$ & 0 & 0 & $3 / 30$ & 10.0 & $\mathrm{P}<0.05$ \\
\hline
\end{tabular}

\section{DISCUSSION}

Total no of deliveries was 2030 out of which 510 were cesarean sections. Out of 90 cesarean sections studied in the study period 30 sections were performed in second stage of labour and 60 sections were performed in first stage of labour. Majority of women were in the age group 20- 25yrs. In both first and second stage cesarean groups majority of them were primigravidas $(61.7 \%$ and $76.7 \%$ respectively) and majority belonged to gestational age of 38 weeks 1 day-39 weeks.

In a study by Malathi et al and Venigalla Sunitha et al $61 \%$ women were in age group 21-30 years. and primigravidas contributed to $74 \%$ of patients undergoing second stage cesarean. The increased frequency of second stage cesarean section in primigravidas could be because of cephalopelvic disproportion, rigid perineum and lack of experience of previous labour. In present study Arrest of descent-Malposition is the most common indication for second stage cesarean section accounting for $76.7 \%$ of cases others are Arrest of descent-CPD and Failed vacuum which accounted for $20 \%$ and $3.3 \%$ of cases respectively.

In first stage cesarean section group the most common indication was failed induction $33.3 \%$ followed by fetal distress $28.3 \%$, failure to progress $20 \%$, Arrest of dilatation $15 \%$ and MSAF $3 \%$. The majority of women delivered by cesarean in second stage were in spontaneous labour and may represent arrest of labour due to malposition or true cephalopelvic disproportion.

Allen et al had compared the maternal and neonatal morbidity of cesarean section in first and second stage of labour in retrospective study. The maternal morbidities can be due to the difficulty in handling the fetus impacted in maternal pelvis. The unfavorable neonatal outcomes are probably due to prolonged labour which leads to hypoxia.

Estimated blood loss, PPH and need for blood transfusion all were greater in second stage cesarean group. In present study women who delivered by cesarean in second stage of labour experienced $\mathrm{PPH}$ in $76.7 \%$ of cases compared to only $10 \%$ of cases in first stage cesarean group and $53.3 \%$ of cases in second stage cs group had excessive blood loss and needed blood transfusion. Rabiu et al found that women who had cesarean deliveries performed in second stage had longer operative time, greater blood loss, more cases of intraoperative trauma, primary $\mathrm{PPH}$, blood transfusion, re look laparotomy, hysterectomy, post-partum pyrexia wound infection and a longer hospital stay.

In present study mean operative time for cesarean section in second stage was 53.3 minutes as compared to 41 minutes for first stage cesarean section owing to difficulties encountered in performing cesarean in second stage.

During the surgery 2 cases who delivered by cesarean in second stage had uterine tear whereas none had bowel and bladder injury. In present study post op fever was noted in $36 \%$ and post op wound infection in $13.3 \%$ of cases who delivered by second stage cesarean section and contributing to relatively longer duration of stay in the hospital mean duration of 6.9 days. There was no case of maternal mortality reported in either of the groups.

There were controversies regarding the fetal outcome in cases of cesarean section in second stage of labour. Study by Ayhun Sucak, Asicioglu, Malati and others had proved adverse prognostic impact on fetal outcome. But many studies like Allen et al, Alexander, Selo-ojeme and others failed to demonstrate an increased incidence of fetal complications. In present study $16.7 \%$ of neonates born by LSCS in second stage had low APGAR scores 
$<3$. Sixteen neonatal cases had respiratory distress and needed resuscitation but 3 cases could not be revived back. There were no cases of neonatal deaths reported in first stage cesarean group. This indicates that cesarean performed during second stage of labour is associated with increased incidence of fetal distress, septicemia, admission to NICU and fetal death. The unfavorable neonatal outcomes are probably due to prolonged labour which leads to hypoxia. ${ }^{6}$ Cesarean section increases the risk in subsequent pregnancies of uterine rupture, which can lead to fetal death or serious fetal hypoxic injury. Cesarean section also increases the risk of placenta previa, placental abruption, and invasive placental disease. Maternal risk from Cesarean section includes increase maternal mortality. ${ }^{7}$ In women who deliver by Cesarean section, maternal mortality is 4-fold that of the maternal population that delivers vaginally. The woman is at increased anaesthetic risk, particularly due to aspiration, and risk of increased blood loss, infection, venous thromboembolism and surgical injury to bladder and bowel.

When operative intervention in the second stage of labour is required, the options, risks, and benefits of vacuum, forceps, and Cesarean section must be considered. ${ }^{8}$ The choice of intervention needs to be individualized, as one is not clearly safer or more effective than the other. Failure of the chosen method, vacuum and/or forceps, to achieve delivery of the fetus in a reasonable time should be considered an indication for abandonment of the method. ${ }^{9}$ Adequate clinical experience and appropriate training of the operator are essential to the safe performance of operative deliveries.

The proportion of cesarean deliveries performed in the second stage of labor is projected to increase for several reasons. First, there has been a decline in the use of rotational and midpelvic forceps delivery. Operative vaginal delivery rates have decreased in general with a shift toward vacuum-assisted vaginal delivery. Second, there is a national trend toward increased utilization of regional analgesia, which can prolong the duration of the second stage. The Obstetric Care Consensus- Safe Prevention of the Primary Cesarean Delivery endorsed by both the American College of Obstetricians and Gynecologists and the Society for Maternal-Fetal Medicine recommends that nulliparous women be allowed 3 hours and multiparous women 2 hours for pushing without epidural analgesia. A longer duration may be allowed in women receiving epidural analgesia. ${ }^{10}$ Allen et. al had compared the maternal and neonatal morbidity of the cesarean section in the first and second stage of labour in a similar but retrospective study. In present study there were no cases of ureter or bladder injury. In present study 16 out of 30 cases in second stage CS required blood transfusion while only 4 out of 60 cases in first stage required transfusion.

In addition, maternal morbidity, including longer operation time, increased hospital stays, transfer to the intensive care unit and infectious maternal morbidity increased. ${ }^{11}$ Neonatal outcome was controversial in previous studies, particularly the risk of fetal asphyxia. Alexander and Selo-Ojeme et al found no difference in the risk of fetal asphyxia. ${ }^{12}$ However, we believe that cesarean delivery performed during the second stage of labour increases the incidence of fetal injury, septicemia, admission to the neonatal intensive care unit and fetal death due to fetal head impaction into the maternal pelvis and prolonged second stage labour. Thus, this may have led to the increased incidence of fetal asphyxia and the decrease in 5 minutes Apgar scores. A recent study by Radha et al. demonstrated a statistically significant increase in birth asphyxia, admission to the neonatal intensive care unit, sepsis, seizures, need for ventilation and neonatal death.

\section{CONCLUSION}

Cesarean section performed during second stage of labour is technically difficult because fetal head engagement in the maternal pelvis has already been completed and maternal uterine muscles are very thin and tense. Additionally, identification of bladder and lower uterine segment of uterus is difficult. These factors contributing to increased duration of surgery and increased intraoperative complications.

Women delivered by cesarean in second stage have a higher risk of post-partum hemorrhage, operative morbidity with visceral injury, sepsis and prolonged hospital stay. Hence it is recommended that second stage cesarean should ideally performed and supervised by an experienced obstetrician. Timely decision for cesarean section should be taken especially when risk factors for failure to progress are present and there should be good neonatology support.

\section{Funding: No funding sources}

Conflict of interest: None declared

Ethical approval: The study was approved by the Institutional Ethics Committee

\section{REFERENCES}

1. Notzon FC, Cnattingius S, Bergsjø P, Cole S, Taffel $\mathrm{S}$, Irgens L, Daltveit AK. Cesarean section Delivery in the 1980's: International comparison by indication. Ame J Obstet Gynecol. 1994;170(2):495-504.

2. Menticoglou SM, Manning F, Harman C, Morrison I. Perinatal outcome in relation to second stage duration. Am J Obstet Gynecol. 1995;173(3):906-12.

3. Murphy DJ, Liebling RE, Verity L, Swingler R, Patel R. Early maternal and neonatal Morbidity associated with operative delivery in second stage of labour: a cohort study. Lancet. 2001; 358(9289):1203-7.

4. Gifford DS, Morton SC, Fiske M, Keesey J, Keeler E, Kahn KL. Lack of progress in labor as a Reason for cesarean. Obstet Gynecol. 2000; 95(4):589-95 
5. Villar J, Valladares E, Wojdyla D, Zavaleta N, Carroli G, Velazco A, et al. Caesarean delivery rates and pregnancy outcomes: the 2005 WHO global survey on maternal and perinatal health in Latin America. Lancet. 2006;367(9525):1819-29.

6. Levy R, Chernomoretz T, Appelman Z, Levin D, Or $\mathrm{Y}$, Hagay ZJ. Head pushing versus reverse breech extraction in cases of impacted fetal head during Cesarean section. Eur J Obstet Gynecol Reprod Biol 2005;121(1):24-6.

7. Sucak A, Çelen Ş, Akbaba E, Soysal S, Moraloglu O, Danışman N. Comparison of nulliparas Undergoing cesarean section in first and second stages of labour: a prospective study in a tertiary Teaching hospital. Obstetrics and gynecology international. 2011; 2011.

8. Landon MB, Hauth JC, Leveno KJ, Spong CY, Leindecker S, Varner MW, et al. Maternal and perinatal outcomes associated with a trial of labor after prior cesarean delivery. New Engl J Med. 2004;351(25):2581-9.

9. Fasubaa OB, Ezechi OC, Orji EO, et al. Delivery of the impacted head of the fetus at caesarean section after prolonged obstructed labour: a randomized comparative study of two methods. J Obstet Gynaecol. 2002;22(4):375-8.
10. Allen VM, Baskett TF, O`Connell CM, McKeen D, Allen AC. Maternal and perinatal Outcomes with increasing duration of the second stage of labor. J Obstet Gynaecol. 2009;113(6):1248-58.

11. Pergialiotis V, Vlachos DG, Rodolakis A, Haidopoulos D, Thomakos N, Vlachos GD. First Versus second stage $\mathrm{C} / \mathrm{S}$ maternal and neonatal morbidity: a systematic review and metaanalysis. European Journal of Obstet Gynecol Reproduct Biol. 2014;175:15-24.

12. Alexander JM, Leveno KJ, Rouse DJ, Landon MB, Gilbert S, Spong CY, Varner MW, Moawad AH, Caritis SN, Harper M, Wapner RJ. Comparison of maternal and infant outcomes From primary cesarean delivery during the second compared with first stage of labor. J Obstet Gynaecol. 2007;109(4):917-21.

Cite this article as: Anusha SR, Deepak AV, Jacob KJ. Maternal and neonatal outcome in second stage cesarean section versus first stage: a comparative study. Int J Reprod Contracept Obstet Gynecol 2018;7:4640-5. 